\title{
Improving the Learning Experience and Outcomes in Entrepreneurial Courses
}

\author{
Diego Alonso, Juan Pastor, Bárbara Álvarez \\ División de Sistemas e Ingeniería Electrónica \\ Universidad Politécnica de Cartagena, Spain
}

\author{
Tanya Suarez \\ BlueSpecs \\ Madrid, Spain
}

\author{
Igor Tasic \\ Barrabés Next \\ Madrid, Spain
}

\begin{abstract}
Entrepreneurship has been gaining momentum is Europe over the last years as a way to reduce unemployment levels, and in line with the take-off of the digital economy in the world. Entrepreneurship education is still an open research area, with many courses being launched in almost all universities. We describe our experience in running a summer school and mentoring the teams created in the context of the EU-XCeL project, and ICT focused project funded by European Union's Horizon 2020 Research and Innovation Programme. From this experience, we extract some conclusions and recommendations for preparing better courses and learning experiences, and we also advocate for courses mixing students from different Degrees studies, mainly Engineering and Business, for improving the experience and the course outcomes, especially for students of Engineering Degrees.
\end{abstract}

Keywords- entrepreneurship education; entrepreneurship curriculum; mixed teams

\section{INTRODUCTION}

Entrepreneurship has been gaining momentum is Europe over the last years as a way to reduce unemployment levels, which have rates of over $50 \%$ for under- $25 \mathrm{~s}$ among Mediterranean countries. Since the first reports on the need to foster entrepreneurial activity [1], the European Commission (EC) has gradually increased its supportive actions with the aim of getting closer to the effectiveness, scale and impact of the entrepreneurial activity in the US [2]. Despite the European Single Market was established in 1993, there are still some barriers that must be overcome to have a fully working and integrated European-wide ecosystem.

The EC created in 2015 the 'Digital Single Market' strategy, one of its current 10 political priorities, with the objective of creating new opportunities for people and business in the new digital economy, and to also make Europe a world leader in it. Among the promoted initiatives, it created Startup Europe (http://startupeuropeclub.eu) and launched two H2020 calls: ICT-35-2014 Innovation and Entrepreneurship Support, and ICT-13-2014 Web Entrepreneurship. Startup Europe aims to strengthen the entrepreneurial ecosystem for web and ICT startups, so that they can grow in Europe. It promotes initiatives for fostering education in entrepreneurship, celebrating success, connecting regional ecosystems, getting to know other ecosystems (like Silicon Valley, India, or Africa), etc.

There are more and more events nowadays dedicated to entrepreneurship activities (check all that took place in 2016 in http://startupeuropeclub.eu/events/), conferences and courses are created specifically to address this topic, and already established courses and conferences are gradually including entrepreneurship issues. For instance, technical track 14 in ISIE 2017, "Entrepreneurship and Management - Challenges for Industrial Electronics", is a new addition.

There are many papers about entrepreneurship education, and it is still an open research area. A thorough review of the empirical literature on university-based entrepreneurship education can be found in [4]. This paper focuses on the educational facet of entrepreneurship and, based on the results of the EU-XCeL project, advocates for mixed, i.e. involving students from technical and business studies, educational and action-based programmes for teaching it. EU-XCeL (http://euxcel.eu), Accelerating entrepreneurial learning across European Regions, is a project funded by European Union's Horizon 2020 Research and Innovation Programme (ICT-35) under Grant Agreement No 644801. It comprises six partners from different European countries with a mix of backgrounds: four partners have expertise in business and entrepreneurship, while the other have a technological background.

The EU-XCeL project (described in Section II) organized six training weeks (entitled 'Startup Scrum') in 2015. In each 'Startup Scrum', around 42 participants from more than 10 European countries met, created international teams, and worked remotely together for three months for developing a business idea. In total, 250 persons from 24 European countries participated in the first edition of EU-XCeL. We describe our experience in running the 'Startup Scrum' in Spain, and mentoring the teams created there (described in Section III). From this experience, we extract some conclusions and recommendations for preparing better courses and learning experiences in Section IV.

\section{SUMMARY OF EU-XCEL}

For the purposes of the design of the EU-XCEL curriculum, we adopted the definition of entrepreneurship proposed in Gartner's behavioral approach [5], where it is stated that entrepreneurship is not a fixed state of existence, but rather it is a role that certain individuals adopt to create organizations. Therefore, we wanted EU-XCEL to emphasize action-based learning and new venture creation through an experiential reallife practice, with the help of mentors. Above all, we wanted participants to have a real-life experience, since in the case of entrepreneurship, it has been demonstrated that this kind of experience, learning by doing in teams and networking, achieves the best results [6].

The design of the EU-XCeL curriculum, and the two phases described below, is based on the conceptual frameworks described in [7], [8] for designing and assessing education 
programs in entrepreneurship. We designed an intensive training experience over 3 months, that comprises 1 face-to-face training week, and 12 weeks of virtual incubation afterwards (see Fig. 1).

The virtual incubation phase ends with the presentation of a (reduced version of a) business plan summarizing the team's venture. We decided to follow a competition approach, where all teams created during a 'Startup Scrum' event in one of the partners' facilities will compete locally. An international jury will afterwards select the best two or three teams of every 'Startup Scrum' to compete again in what we called "The BornEuropean Final Challenge". The competition approach helps keeping the momentum created during the training week, and offers participants an incentive to continue working together remotely during the virtual incubation phase. The "Final Challenge" was organized to reunite teams again after 3 months of virtual work, to improve the participants' network of contact, and to pitch to business angels, venture capitalists, and successful tech entrepreneurs for the prize.

EU-XCeL was repeated six times in 2015, once in each of the partners' facilities, from May to July. Each partner was given the freedom to slightly adopt the execution of the Startup Scrum to match his/her usual practices, knowledge, and particularities. The EU-XCeL curriculum is supported by a Moodle course, so that participants can access shared materials (slides, videos, articles, etc.), and upload reports on their advancements.

\section{A. Training Week}

The curricular structure and the sequence of activities carried out during the training week is shown in Fig. 1. We selected several innovation and entrepreneurial frameworks and theories currently available in the literature to design this week. The main contents revolve around Lean Startup [9] and Design Thinking [10], but we also included other theories, such as Effectuation [11], The New Business Road Test [12], Getting to plan B [13], and Business Model Generation [14], to mention but a few. Another, very important topic is remote work and management of virtual teams, since participants had to work together developing their business idea remotely for 12 weeks. We employed current practices and research findings [15], [16] to develop and present virtual team work.

As shown in Fig. 1, and coinciding with the lean spirit, we presented participants an iterative entrepreneurship development process. In fact, it is a simplified version of the process they should follow over the virtual incubation phase. We advised participants that the process is iterative, in the sense that they may need to come back to previous steps if need, e.g. if they realize the product does not fulfil a real need. And this could happen at any point of time during the EU-XCeL program.

We asked participants to deliver three documents by the end of the week: (i) an action plan summarizing their plans for the virtual incubation phase, (ii) a team manifesto, where they discus intellectual property, team management and communication, their vision and roles, etc., and (iii) a presentation of their initial business idea. All teams have to upload these documents by the end of the week, and all teams present their work on Friday on a pitching session where they have 7 minutes for making the presentation, and then receive 10 minutes of feedback.

The objective for the first day is team formation, which has demonstrated to be one of the hardest and most critical steps of the week. EU-XCeL aims at creating "born European" startups, that is, startups that could open business in more than one European country at the same time. To achieve this objective, we imposed the following restrictions on team formation: teams should be made up of participants from at least three different countries, and with no more than two members with the same nationality. Besides these restrictions, we advised them to make teams with 4 to 6 members, and to find the most feasible set of team roles and business/technical skills to successfully develop their idea, in the line of what is described in [17].

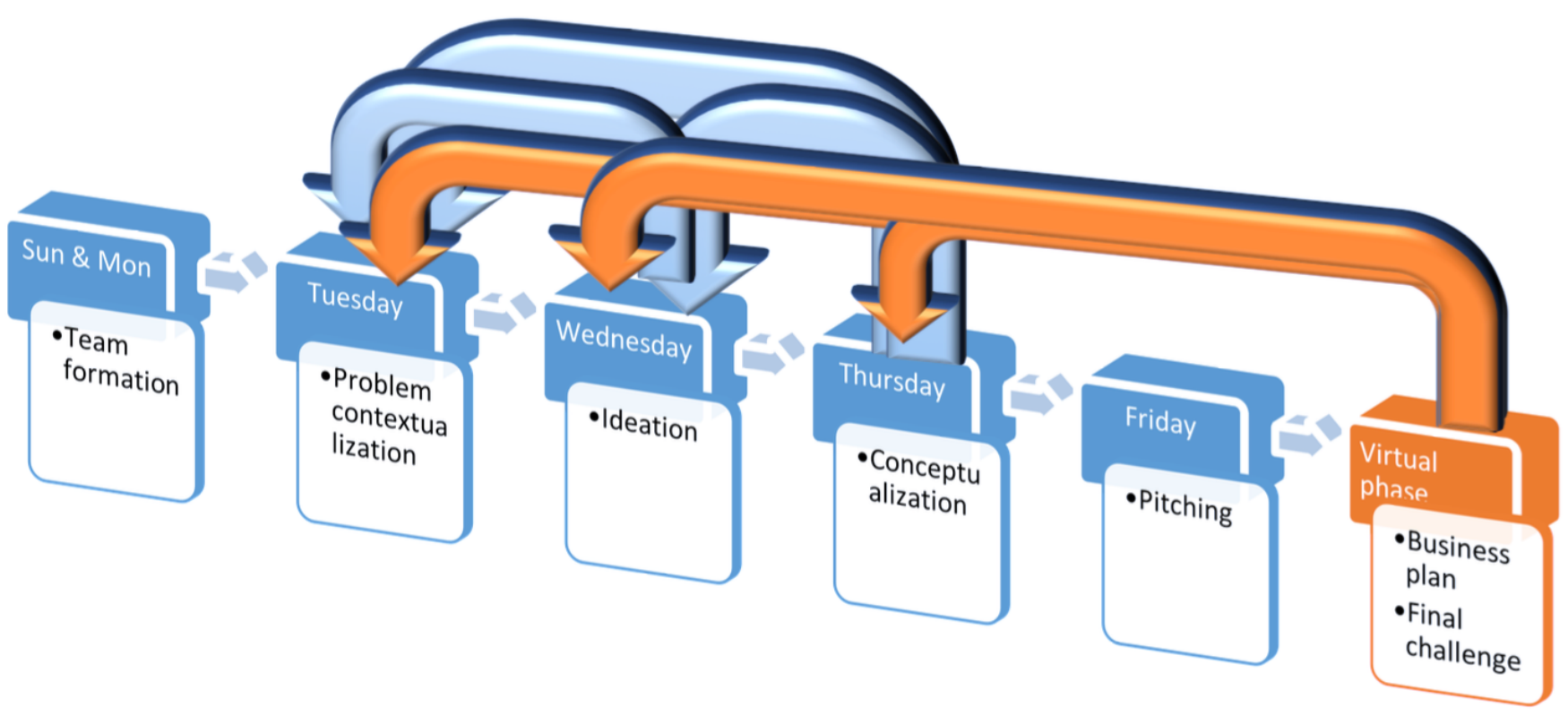

Fig. 1. Organization of EU-XCeL: training week and virtual phase. It is an iterative development cycle, since at any point of time it may be necessary to go back to a previous step. 
We also advised them to find participants with whom they share personal values, plans and hopes for the future, and commitment level (e.g., are willing to work a similar number of hours per week). We allowed participants to change team any time during the week, but not after it. Sunday and Monday were devoted to team formation, with activities selected to ease the process of getting to know other participants. We run icebreaking activities like Bingo!, and workshops such as World Café. We also planned socializing activities outside the venue, in a more relaxed environment.

The following three days (from Tuesday to Thursday) were devoted to lectures and workshops about the entrepreneurship process: from idea generation and evaluation (by using mainly brainstorming techniques), to idea validation (searching, making interviews and market segmentation), and business plan elaboration (business model canvas). There is also a lecture on prototyping, since the objective of EU-XCeL is to create ICT startups; but we emphasize that the first objective of the team is to get the business idea right, and that they must work mainly on idea validation through fast prototyping.

We allocated time for the teams to work on idea generation and early validation during the week. Mentors are also introduced to them at some point, and we ask them to work together for some time so that they can build a trust relationship. Mentors support the team over the virtual incubation phase, supervising their work and having at least one meeting once a week to keep momentum and solve any issue that could arise.

\section{B. Virtual Incubation}

The virtual incubation phase starts just after the training week and lasts for 12 weeks. Teams must develop their initial business idea over these weeks, working mainly on problem validation and idea development with the help of low fidelity prototypes. Teams follow basically the Lean Startup development cycle, designing their Minimum Viable Product (MVP), evolving it and their idea as they receive feedback from potential customers, mentors, and other stakeholders.

We also designed the activities the teams should fulfil during the virtual incubation phase, and prepare a set of periodic reports to guide them through the process. 12 weeks is a long period of time, and we thought teams could get lost in the entrepreneurial process if they were left unguided. In order to avoid this problem, teams had to upload a periodic report of their activity every two weeks, summarizing what they had performed during that week regarding the following objectives and the activities listed in Table I:

1) Week 2: problem validation and stakeholders identification.

2) Week 4: initial idea development (development of MVP $_{1}$ based on the team's initial assumptions).

3) Week 6: initial proof of concept (stakeholders feedback on $\mathrm{MVP}_{1}$ ).

4) Week 8: idea further development (evolution of $\mathrm{MVP}_{1}$ to $\mathrm{MVP}_{2}$ based on received feedback).

5) Week 10: proof of concept (stakeholders feedback on $\left.\mathrm{MVP}_{2}\right)$.
6) On week 12, teams have to submit a reduced version of a business plan, describing their venture in 15 pages or less. This is the document the jury will use to shortlist the teams for the Final Challenge.

TABLE I. MILESTONES AND ACTIVITIES FOR THE VIRTUAL INCUBATION PHASE

\begin{tabular}{|c|c|c|}
\hline $\begin{array}{l}\text { Virtual } \\
\text { phase stage }\end{array}$ & Outcome & Support activities \\
\hline Week 2 & $\begin{array}{c}\text { Problem } \\
\text { validation }\end{array}$ & $\begin{array}{l}\text { 1. Desk research findings } \\
\text { 2. Stakeholder research } \\
\text { 3. Reference site development } \\
\text { 4. Technical feasibility analysis } \\
\text { 5. Customer analysis }\end{array}$ \\
\hline Week 4 & $\begin{array}{l}\text { Business model } \\
\text { refinement }\end{array}$ & $\begin{array}{l}\text { 1. Value proposition } \\
\text { 2. Market sizing } \\
\text { 3. Market segmentation } \\
\text { 4. Competitor analysis } \\
\text { 5. SWOT analysis } \\
\text { 6. Stakeholder map } \\
\text { 7. Technical feasibility analysis }\end{array}$ \\
\hline Week 6 & $\begin{array}{l}\text { Initial proof } \\
\text { of concept }\end{array}$ & $\begin{array}{l}\text { 1. Key research findings } \\
\text { 2. Reference site feedback } \\
\text { 3. Idea validation }\end{array}$ \\
\hline Week 8 & Idea elaboration & $\begin{array}{l}\text { 1. Detailed business model } \\
\text { 2. Strategic positioning } \\
\text { 3. Detailed segment analysis } \\
\text { 4. Draft business plan } \\
\text { 5. Technical demonstration }\end{array}$ \\
\hline Week 10 & $\begin{array}{c}\text { Advanced proof } \\
\text { of concept }\end{array}$ & $\begin{array}{l}\text { 1. Marketing strategy } \\
\text { 2. Financial plans } \\
\text { 3. Go-to-market strategy } \\
\text { 4. Technical demo findings }\end{array}$ \\
\hline Week 12 & $\begin{array}{l}\text { Implementation } \\
\text { roadmap }\end{array}$ & $\begin{array}{l}\text { 1. Available technical demo or } \\
\text { accessible platform } \\
\text { 2. Website landing page and } \\
\text { social media presence } \\
\text { 3. Business plan document }\end{array}$ \\
\hline
\end{tabular}

Taking inspiration from the Lean Startup methodology, the virtual incubation phase considers two fast cycles of the "BuildMeasure-Learn" [9] loop, for a total of 8 weeks of work. Given that the teams are still defining their idea and product, we told them to develop their MVP by using fast prototyping tools (such as http://proto.io), or mock-ups of their product. This design of the virtual incubation phase highlights the importance of developing the product iteratively and as fast as possible, while at the same time it allows teams to rethink and re-validate their idea, and redesign their product if needed.

\section{TEAMS MADE IN SPAIN IN 2015}

Table II summarizes the background of the participants and the teams created at the Startup Scrum that took place in Cartagena, Spain, from July the $6^{\text {th }}$ to the $10^{\text {th }}$. The Startup Scrum involved a total of 42 participants from 12 European countries. 17 participants had or were studying Business or Law Degrees, while 25 had technical background in Engineering (Telecommunication, Electrical, Product Design, etc.) or Computer Science. The age of participants ranged from 21 to 33 years old, with 13 female and 29 male participants. 
TABLE II. SCRUM PARTICIPANTS AND TEAM SUMMARY, 2015 (I)

\begin{tabular}{|c|c|c|c|c|c|c|c|}
\hline Team \# & Product & Country & $\begin{array}{l}\text { Age } \\
\text { range }\end{array}$ & $\begin{array}{c}\text { Highest } \\
\text { education level }\end{array}$ & $\begin{array}{l}\text { Education } \\
\text { discipline }\end{array}$ & $\begin{array}{c}\text { Working exp. } \\
\text { (months) }\end{array}$ & $\begin{array}{c}\text { Had business } \\
\text { idea }\end{array}$ \\
\hline \multirow{5}{*}{1} & \multirow{5}{*}{$\begin{array}{l}\text { Hardware, } \\
\text { software } \\
\text { and web } \\
\text { application } \\
\text { (wereable } \\
\text { for kids) }\end{array}$} & Poland & $28-32$ & Master & Business & $36+$ & Yes \\
\hline & & Ireland & $28-32$ & Master & Business & $7-18 \pi$ & No \\
\hline & & Spain & $<23$ & Post-Secondary & Engineering $\curvearrowright$ & none & Yes \\
\hline & & Spain & $<23$ & Degree & Engineering & $7-18 \kappa$ & Yes \\
\hline & & Ireland & $<23$ & Degree & Engineering & $36+\pi$ & No \\
\hline \multirow{5}{*}{2} & \multirow{5}{*}{$\begin{array}{l}\text { Web } \\
\text { application } \\
\text { (wedding } \\
\text { management) }\end{array}$} & Denmark & $23-27$ & Post-Secondary & Innovation/Design & $1-6 \uparrow$ & Yes \\
\hline & & Greece & $23-27$ & Post-Secondary & Business $\curvearrowright$ & $19-36$ & Yes \\
\hline & & Denmark & $23-27$ & Post-Secondary & Innovation/Design & $19-36 \pi$ & No \\
\hline & & Germany & $28-32$ & Degree & Computer Science & $19-36 \pi$ & Yes \\
\hline & & Greece & $<23$ & Post-Secondary & Business $\curvearrowright$ & $19-36$ & Yes \\
\hline \multirow{5}{*}{3} & \multirow{5}{*}{$\begin{array}{l}\text { Software } \\
\text { and web } \\
\text { application } \\
\text { (education } \\
\text { advice) }\end{array}$} & Netherlands & $<23$ & Degree & Business & $7-18 爪$ & Yes \\
\hline & & Bosnia Herz. & $23-27$ & Degree & Computer Science & $19-36 \pi$ & Yes \\
\hline & & Bosnia Herz. & $23-27$ & Degree & Computer Science & $19-36 \pi$ & Yes \\
\hline & & Denmark & $23-27$ & Degree & Innovation/Design & $7-18 \uparrow$ & No \\
\hline & & Sweden & $23-32$ & Degree & Humanities \& Law & $36+$ & Yes \\
\hline \multirow{5}{*}{4} & \multirow{5}{*}{$\begin{array}{l}\text { Web } \\
\text { application } \\
\text { (musicians) }\end{array}$} & Spain & $<23$ & Degree & Computer Science & $1-6 \pi$ & Yes \\
\hline & & Greece & $23-27$ & Master & Business & $36+\pi$ & No \\
\hline & & Spain & $<23$ & Post-Secondary & Engineering $>$ & $19-36 \uparrow$ & No \\
\hline & & Greece & $23-27$ & Degree & Business & $19-36 \pi$ & Yes \\
\hline & & Germany & $23-27$ & Degree & Computer Science $\curvearrowright$ & $7-18$ & Yes \\
\hline \multirow{5}{*}{5} & \multirow{5}{*}{$\begin{array}{l}\text { Software } \\
\text { and web } \\
\text { application } \\
\text { (children } \\
\text { education) }\end{array}$} & France & $<23$ & Post-Secondary & Engineering & $1-6 \uparrow$ & Yes \\
\hline & & Belgium & $23-27$ & Post-Secondary & Computer Science & $7-18$ & Yes \\
\hline & & Spain & $<23$ & Post-Secondary & Computer Science & none & No \\
\hline & & Germany & $28-32$ & Bachelor Degree & Engineering & $7-18$ & No \\
\hline & & Greece & $23-32$ & Bachelor Degree & Business $\curvearrowright$ & $36+\pi$ & Yes \\
\hline \multirow{6}{*}{6} & \multirow{6}{*}{$\begin{array}{l}\text { Software } \\
\text { (online } \\
\text { marketing) }\end{array}$} & Spain & $23-27$ & Post-Secondary & Engineering $\curvearrowright$ & none & Yes \\
\hline & & Libano & $23-27$ & Master & Engineering & $7-18$ & Yes \\
\hline & & Poland & $28-32$ & Degree & Business & $36+$ & No \\
\hline & & Spain & $23-27$ & Post-Secondary & Engineering $\curvearrowright$ & $7-18$ & Yes \\
\hline & & Germany & $28-32$ & Master & Business $\curvearrowright$ & $36+\pi$ & Yes \\
\hline & & Greece & $<23$ & Post-Secondary & Business $\curvearrowright$ & none & No \\
\hline \multirow{4}{*}{7} & \multirow{4}{*}{$\begin{array}{l}\text { Web } \\
\text { application } \\
\text { (grocery } \\
\text { management) }\end{array}$} & Ireland & $23-27$ & Post-Secondary & Business $\curvearrowright$ & $36+\pi$ & Yes \\
\hline & & Germany & $28-32$ & Master & Computer Science & $36+\pi$ & Yes \\
\hline & & Ireland & $<23$ & Post-Secondary & Business $\curvearrowright$ & $1-6$ & No \\
\hline & & Poland & $23-27$ & Degree & Business $\curvearrowright$ & $36+\pi$ & No \\
\hline \multirow{6}{*}{8} & \multirow{6}{*}{$\begin{array}{l}\text { Web } \\
\text { application } \\
\text { (flash } \\
\text { advertising) }\end{array}$} & Netherlands & $28-32$ & Master & Law & $36+\pi$ & Yes \\
\hline & & Denmark & $28-32$ & Bachelor Degree & Computer Science & $36+\pi$ & Yes \\
\hline & & Denmark & $28-32$ & Master & Business $\curvearrowright$ & $36+\pi$ & No \\
\hline & & Belgium & $<23$ & Bachelor Degree & Computer Science & $1-6$ & Yes \\
\hline & & Spain & $23-27$ & Post-Secondary & Engineering & $1-6$ & Yes \\
\hline & & Poland & $23-27$ & Bachelor Degree & Business & $7-18$ & No \\
\hline
\end{tabular}


We had $1 \mathrm{PhD}$ candidate, 4 participants had a Master degree, 15 were currently studying a Master, 24 Graduates, and 18 participants were finishing their Degree studies. Almost all participants had prior working experience, and some of them were working at that time. Finally, 23 participants had some previous experience on entrepreneurship, mainly due to a university course or because they were entrepreneurs themselves. The mean team size was 5 participants, and all teams had at least one member with technical and business background, although the mean was to have a couple of members with such backgrounds.

After the end of the 'Startup Scrum', we sent participants a questionnaire to evaluate the experience, ask them about the main learnings and competences they have acquired/improved over the whole EU-XCeL programme. The results of this questionnaire are shown in Figure 2.

Regarding the "Final Challenge", team 8 was the winner of the Cartagena 'Startup Scrum' and classified to the final, which took place in Cork in November 2015. Teams 1 and 3 went to a second round with the second and third teams of each of the other 'Startup Scrums', but they were not shortlisted for the Final Challenge.

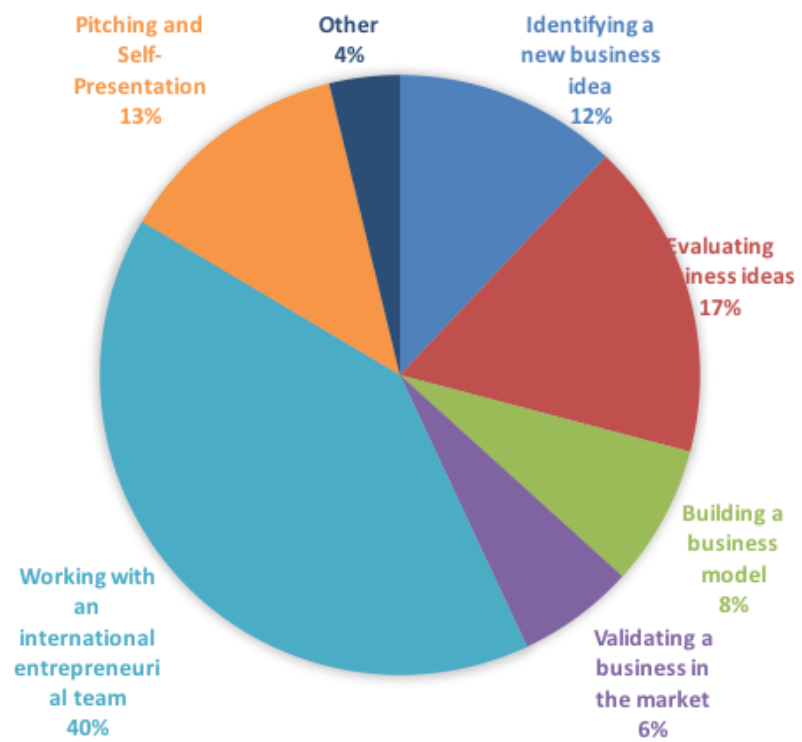

Fig. 2. Questionnaire about the main learnings and acquired/improved compentences over the EU-XCeL programme.

\section{CONCLUSIONS AND LESSONS LEARNT}

Entrepreneurship is seen in Europe as one of the most promising ways of reducing unemployment levels. While this is a well-known fact in the US, entrepreneurship has been gaining momentum in Europe in the last years. Entrepreneurship education is still an open research area, and in this paper, we have described our experience in running an acceleration programme for 3 months in the context of the $\mathrm{H} 2020 \mathrm{EU}-\mathrm{XCeL}$ project. The course involved a mix of 42 participants from 12 European countries with different backgrounds, mainly Engineering and Business, and skills.
The main conclusion we want to highlight, extracted not only from Cartagena 'Startup Scrum' but from the six 'Startup Scrums' all the EU-XCeL run in 2015, is that teams with a mixed set of backgrounds and skills outperform, in general, homogeneous teams. Although this is not new, it can sometimes be forgotten when designing a course. Therefore, we advocate for designing better entrepreneurship education courses by involving students from different, complementary Degree courses. All participants benefit from mixed teams: Engineering students learn that product development comes after idea validation and customer segmentation, while Business students learn about technology and collaborate in the product development phase. And students of both type of Degrees can put into practice their knowledge in a synergistic way. Therefore, we would like to see in the near future this kind of course offered by Universities, either as optional or mandatory. Or even joint bachelor or master thesis, performed by students of both Engineering and Business Degrees in a collaborative way.

Regarding lessons learnt, we think it is more interesting to summarize the experience of the 2015 edition, which involved a total of 250 participants, who created 50 teams that went through the same experience. Teams that had many students performed worse than those which didn't, since the virtual incubation was a bit demanding for them, specially during the exam period. Also, teams that had members with previous working experience, and who weren't working at the moment, performed better, since they took the program more seriously than other participants. That is, unsurprisingly, older participants performed better than younger ones overall.

Teams that had members with previous entrepreneurship experience and organizational skill really stood out from the rest of teams. This was the case of team 8 of Cartagena, where one of its members had previous entrepreneurship experience and management skills. She was the leader and organizer of the team, guiding it through all the phases of the programme and Lean Startup methodology.

Engineers, in general, felt a bit lost and useless during the 'Startup Scrum' week, since most of the lectures and workshops were about the entrepreneurial process, business modeling and alike. And also because the objective of the week was to create teams and start developing a business plan, rather than having a working prototype. Thus, we recommend paying more attention to them, to ensure they understand the entrepreneurial process. But they were nevertheless essential, since they helped during brainstorming sessions to identify the problem that the team wanted to tackle, and they were indispensable to design the ICT product (hardware or software), and make it evolve throughout the posterior 12 week acceleration programme.

Finally, it is worth highlighting the two biggest pitfalls: team formation and virtual team management. Entrepreneurs need teams, teams involve human relationships, and human relationships are complicated. It is very hard to find people with whom you share personal values, plans and hopes for the future, and commitment level, and create trust with them, in just a week. Team formation was hard to finish successfully for everyone because, once a team was formed, the remaining participants knew there were less other participants to form a team. So, it was 
very stressful for them. The restrictions (like no more than 3 participants from same country and making balanced teams, with both technical and business backgrounds) only removed options and created more stress. In some cases, participants even changed teams on Wednesday, when they realized they didn't really like the team they were in for any reason. We found ourselves more often than not giving advice and helping participants find a suitable team. Of course, team formation is not such a big problem in regular university courses, where students know each other for long time, but it definitely was in the case of EU-XCeL project, and it can be in courses that mix students from different Degrees, if they are serious about developing a business idea and making it real.

But after they have a team for the 'Startup Scrum', participants have to keep it alive while working remotely at home. This was a critical step too, since some teams lost momentum and stopped working, while others needed some kind of "team therapy" sessions to continue working together, because some misunderstandings and disagreements appeared among the team members. Some of the guidelines we provided them, that can be useful for any kind of entrepreneurial course, are (i) define a fix schedule for having meetings and working on the project (and commit to it); (ii) assign responsibilities with deadlines, considering task dependencies; (iii) create a shared repository for documentation, or use any of the available online team management tools; and (iv) agree on rules to prevent and resolve conflicts, since they will eventually arise. And in the case of virtual teams, it is recommendable to (i) have weekly meetings with video streaming; (ii) create a hierarchical messaging plan and set expectations for reply; (iii) take into account cultural and time zones differences; and of course, (iv) be extra-polite in the communications, since English may not be the mother tongue for everyone. Also, sending an agenda with the main discussions points before the meeting and preparing minutes for everyone also helps in the process.

\section{ACKNOWLEDGMENT}

This work has been developed in the context of the EU$\mathrm{XCeL}$ project, funded by European Union's Horizon 2020 Research and Innovation Programme under Grant Agreement No 644801. It has been partially supported by the "Research Programme for Groups of Scientific Excellence at Region of Murcia" of the Seneca Foundation (Agency for Science and Technology of the Region of Murcia - 19895/GERM/15). Diego Alonso thanks the Spanish Ministerio de Educación, Cultura y Deporte, Subprograma Estatal de Movilidad, Plan Estatal de Investigación Científica y Técnica y de Innovación 2013-2016 for grant CAS14/00238.

\section{REFERENCES}

[1] European Commission, "Green paper: Entrepreneurship in Europe," Enterp. Publ., p. 24, 2003.

[2] N. Davis, "Enhancing Europe's Competitiveness Fostering Innovation-Driven Entrepreneurship in Europe," World Econ. Forum, no. January, pp. 1-38, 2014.

[3] K. Wilson, "Entrepreneurship Education in Europe," in Entrepreneurship and Higher Education, OECD, 2008, pp. 1-20.

[4] E. C. Rideout and D. O. Gray, "Does entrepreneurship education really work? A review and methodological critique of the empirical literature on the effects of university-based entrepreneurship education,” J. Small Bus. Manag., vol. 51, no. 3, pp. 329-351, 2013.

[5] W. B. Gartner, "Who is an Entrepreneur? Is the Wrong Question," Entrep. Theory Pract., vol. 13, no. 4, pp. 47-67, 1989.

[6] E. A. Rasmussen and R. Sørheim, “Action-based entrepreneurship education," in Technovation, 2006, vol. 26, no. 2, pp. 185-194.

[7] N. Ahmad and A. Hoffman, "A framework for addressing and measuring entrepreneurship," Oecd, vol. 2, no. November, pp. 1-421-29-36, 2007.

[8] D. Valliere, S. A. Gedeon, and S. Wise, "A Comprehensive Framework for Entrepreneurship Education," J. Bus. Entrep., vol. 26, no. 1, p. 89,2014

[9] E. Ries, The Lean Startup: How Today's Entrepreneurs Use Continuous Innovation to Create Radically Successful Businesses. Ed. Crown Business, 2011.

[10] T. Brown, "Design thinking," Harv. Bus. Rev., vol. 86, no. 6, 2008.

[11] S. D. Sarasvathy, "Causation and effectuation: Toward a theoretical shift from economic inevitability to entrepreneurial contingency," Acad. Manag. Rev., vol. 26, no. 2, pp. 243-263, 2001.

[12] J. Mullins, The New Business Road Test: What entrepreneurs and executives should do before launching a lean start-up. Ed. Pearson, 2013.

[13] J. Mullins and R. Komisar, Getting to Plan B: Breaking Through to a Better Business Model. Harvard Business Press, 2009.

[14] A. Osterwalder and Y. Pigneur, Business Model Generation: A Handbook for Visionaries, Game Changers, and Challengers. Ed. Wiley, 2010.

[15] L. J. Gressgård, "Virtual team collaboration and innovation in organizations," Team Perform. Manag., vol. 17, no. 1/2, pp. 102-119, 2011.

[16] P. Bjørn and O. Ngwenyama, "Virtual team collaboration: Building shared meaning, resolving breakdowns and creating translucence," Inf. Syst. J., vol. 19, no. 3, pp. 227-253, 2009.

[17] R. Bakker, F. Bogerd, Z. He, W. Mieras, and V. Ssemaganda, "Nobody's perfect, but a team can be," Report 2WX04, Eindhoven University of Technology, Department of Mathematics and Computer Science, 2006. 